\title{
AN INDEX OF MANAGEMENT INTENSITY FOR COFFEE AGROECOSYSTEMS TO EVALUATE BUTTERFLY SPECIES RICHNESS
}

\author{
Alexandre H. Mas and Thomas V. Dietsch ${ }^{1}$ \\ School of Natural Resources and Environment, University of Michigan, Dana Building, 30 East University, \\ Ann Arbor, Michigan 48109-1115 USA
}

\begin{abstract}
In spite of the attention that has been focused on the importance of traditional, shade coffee production for biodiversity, little is known about the relative conservation value of different systems of managing the shade canopy. We surveyed fruit-feeding butterfly species richness and vegetation structure on different shade coffee management systems in Chiapas, Mexico, that ranged from intensive commercial to traditional, rustic systems. The impact of management on the diversity and structure of the shade canopy in each coffee production system was quantified and compared using a Management Index. This Management Index revealed statistically significant differences between management systems that previously were distinguished by researchers using qualitative, "gestalt" categories. Butterfly species richness was found to decline as management intensity increased, but a significant drop was found between the rustic system and the other more intensive systems, corroborating the importance of preserving rustic, shade coffee production for the conservation of biodiversity. Fruit-feeding butterflies were found to be very sensitive to the intensification of management of the shade canopy, so they may be an effective way to monitor ecological changes that accompany intensification within the coffee agroecosystem. Additionally, the vegetation Management Index may prove useful for quantifying management practices to evaluate certification criteria for conservation benefits.
\end{abstract}

Key words: agroecology; agroforestry; biodiversity; Chiapas, Mexico; coffee agroecosystems, fruit-feeding butterflies; intensity gradient; management index; shade-grown coffee.

\section{INTRODUCTION}

Traditional methods of coffee cultivation, in which coffee is grown under diverse forest canopies, have been demonstrated to be compatible with the conservation of tropical biodiversity (Perfecto and Snelling 1995, Moguel and Toledo 1996, Perfecto et al. 1996, Wunderle and Latta 1996, Greenberg et al. 1997a, b). However, the majority of relevant research to date has focused on comparisons of traditional shaded and nontraditional full-sun systems, resulting in little information on the conservation significance of the spectrum of shaded coffee agroecosystems that exist between these extremes. The systems of shade management that fall along this spectrum have generally been differentiated using "gestalt" categories (Toledo and Moguel 1996, Moguel and Toledo 1999). While these categories have been useful in conceptualizing the process of increasing management intensity in initial survey work (Perfecto et al. 1996, Wunderle and Latta 1996, Greenberg et al. 1997a, $b$, Calvo and Blake 1998), they will become more limiting as ecological questions are addressed. Within each gestalt category, for example,

Manuscript received 2 August 2001; revised 19 November 2002; accepted 12 December 2002; final version received 18 February 2003. Corresponding Editor: D. A. Andow.

${ }^{1}$ Corresponding author and present address: Smithsonian Institution, National Zoological Park, Migratory Bird Center, 3001 Connecticut Avenue, NW, Washington, D.C. 200082598 USA. there is considerable spatial and temporal variation in vegetation structure and diversity. This variation increases as management intensity is reduced and the shade canopy becomes more complex.

In order to test more mechanistic hypotheses of how observed patterns of biodiversity are related to management practices, it will therefore be increasingly valuable to draw on more quantitative measures of management intensity. In this study, we developed a Management Index to quantify differences in vegetation structure reflective of management intensity. This index is used to evaluate whether qualitative differences between shade coffee agroecosystems correspond to quantitative differences in vegetation and farm management. Quantitative approaches, such as the development of this index, can help define the conservation potential of a range of shaded coffee farms. An index can be used for comparisons across broad geographic areas or tailored to regional differences in growing conditions and management practices. This kind of index can also help to expand the discussion of biodiversity on coffee farms by allowing more rigorous examination of how differences in management intensity relate to changes in biodiversity. Furthermore, this approach can be adapted for use in other humanmanaged systems where management intensity varies along a gradient. Thus, research in sustainable forestry, agriculture, and other systems where managers seek to balance productivity with biodiversity conservation or 
maintenance of natural features could benefit from implementing a similar vegetative sampling method to calculate an index of management intensity.

Research to date that has examined changes in biodiversity along the spectrum of shade systems has generally focused on birds (Greenberg et al. 1997b, Calvo and Blake 1998), so there is value in exploring how other taxa respond to changes in management. A logical choice for a comparative taxonomic group are insects, which constitute over half of all described species (Groombridge 1992) and which have already been the focus of numerous studies of their potential to serve as indicators of ecological disturbance (Noss 1990, Kremen 1992, 1994, Oliver and Beattie 1993, Brown 1996, Hamer et al. 1997, Lawton et al. 1998). The majority of these studies have focused on the impacts of logging, and many have concentrated their efforts on butterflies as indicators because they are easy to sample, have well-documented natural histories, and have groups that are highly sensitive to habitat disturbance (Sparrow et al. 1994, Brown 1997, DeVries et al. 1997, Wood and Gillman 1998). Moreover, butterflies are a natural choice for evaluating disturbance in the coffee agroecosystem because traditional coffee plantations are widely praised by butterfly collectors as premier spots for sampling a broad diversity of specimens (H. Wagner, personal communication).

In spite of this, butterflies have not yet been included in studies of biodiversity on shaded coffee farms (Moguel and Toledo 1999). Research on butterflies can therefore contribute to a broader base of understanding about the ways in which intensification of coffee management affect biodiversity, and developing and using a Management Index can at last allow a quantitative examination of how differences in management intensity relate, in this case, to differences in butterfly species richness.

\section{Methods}

\section{Study sites and sampling locations}

Fieldwork began in Mexico in the summer of 1998. Mexico is well suited for this work because $89 \%$ of the coffee farms in Mexico maintain some shade canopy and 39\% grow coffee under diverse shade (Moguel and Toledo 1999). Within the state of Chiapas, the Soconusco Mountain range in the south was chosen for this study because it has been identified as a region of high conservation value in Mexico and because it is the region of the state that has been most dramatically affected by programs of coffee intensification (Moguel and Toledo 1999).

Data were collected at two sites within this region: one in the municipality of Tapachula and the other in Huixtla (Fig. 1). Initial groundwork was performed to identify the distinct management systems present and their approximate dimensions. In Huixtla, two areas of coffee cultivation were sampled at Finca Belen, a rustic area with the original native overstory relatively intact (hereafter Belen Rustic) and an area in full production (hereafter Belen Production) under a diverse but managed canopy, with Inga sp. and Alchornia latifolia most abundant. In Tapachula, a similar management area was sampled at Finca Irlanda (Irlanda Production), as well as an area where the owner is planting additional native overstory trees in an attempt to restore a traditional canopy (Irlanda Restoration).

A neighboring farm, Finca Hamburgo, was also included in the study because it represents a more intensive management system (Hamburgo Production) using only Inga sp. for shade. This system was not certified organic, but the owners have greatly reduced agrochemical use, only applying synthetic fertilizers infrequently during the study. All other treatments were certified organic by the International Federation of Organic Agriculture Movements (IFOAM) and Organic Crop Improvement Association (OCIA USA) standards to minimize confounding effects from the use of chemicals hazardous to insects and birds. Small reserves (20-30 ha) of relatively intact forest were present and sampled at both sites (Irlanda Forest and Belen Forest).

In each of these habitats we selected four random sampling locations separated by a minimum $100 \mathrm{~m}$ and located, where possible, $100 \mathrm{~m}$ from edges with other habitat types. The location and shape of the Irlanda Restoration limited distance from the edge to $50 \mathrm{~m}$ in some cases. Samples in all habitats at the Tapachula site were take from 11 to 23 June 1998 and in all habitats at the Huixtla site from 30 June to 11 July 1998. Sampling locations were assigned using a stratified random sampling design within each system, taking into consideration the required buffers between locations and from edge with other management types.

\section{Vegetation sampling}

In this study, we defined shade management as management affecting the diversity and abundance of shade trees, percentage of canopy cover, and structural depth within the canopy. Because the avifauna was also sampled at these locations (data compared in Perfecto et al. 2003), the vegetation protocol used in this study was modified from the Breeding Biology Research and Monitoring Database (BBIRD) protocol (Martin and Geupel 1993). Each sampling location was established as a circle with a radius of $12 \mathrm{~m}$ within which all trees $>8.13 \mathrm{~cm}$ diameter at breast height $(\mathrm{dbh})$ were identified to species when possible or to morpho-species. Height and dbh were recorded for each tree, as were the presence or absence of epiphytes, fruit, or flowers. Within a 5-m radius, the same data were collected for understory trees with a dbh of $2.54-8.13 \mathrm{~cm}$. Since this study focused on coffee management systems, the total number of coffee bushes within the $12-\mathrm{m}$ radius was recorded for each location, as were the heights of all bushes within a 5-m radius. 


\section{Finca Irlanda}
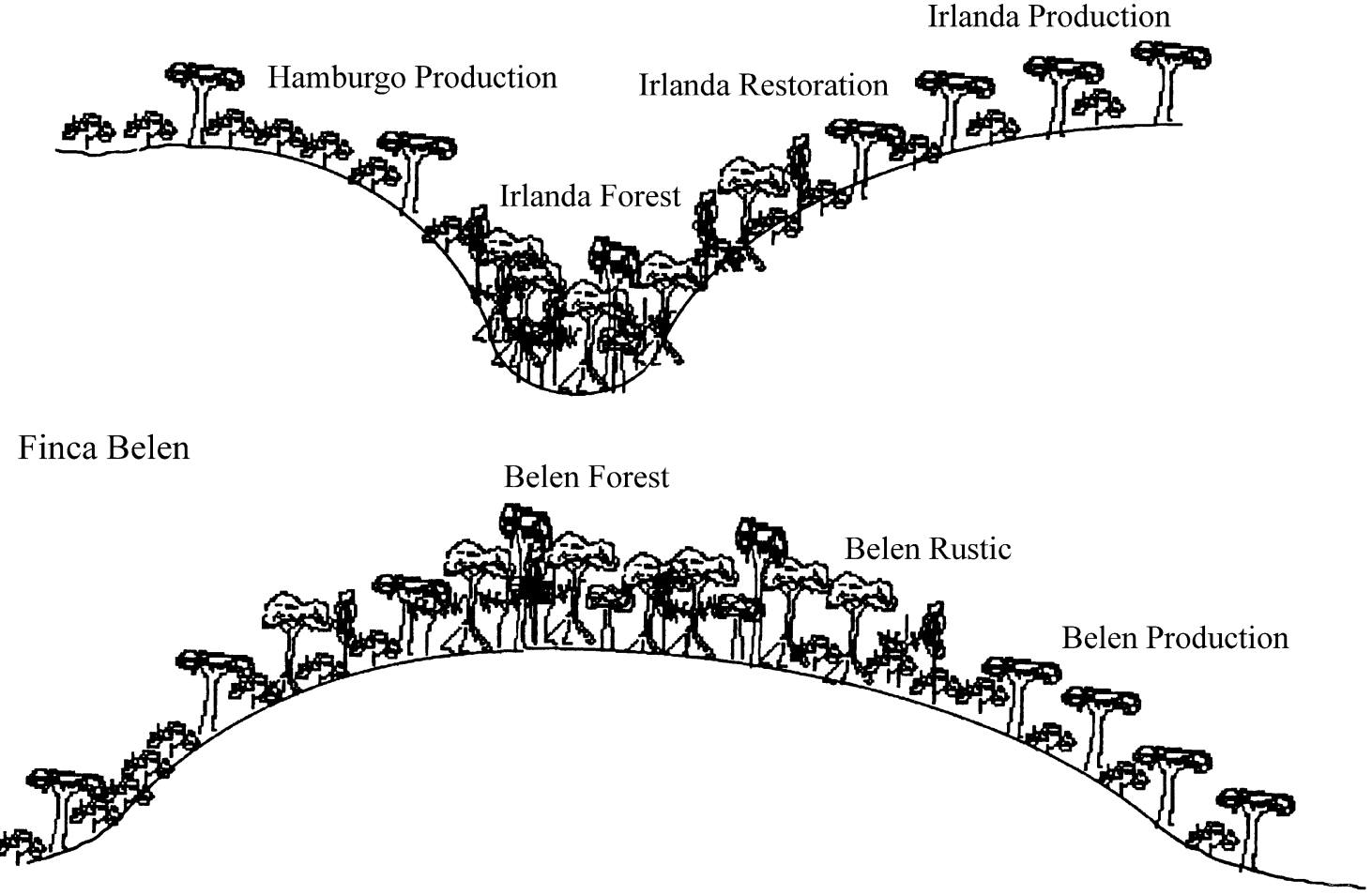

FIG. 1. Schematic cross section of both study sites with all management systems labeled. Altitude ranged from $880 \mathrm{~m}$ in the lowest Irlanda Forest sample location to $1200 \mathrm{~m}$ in the highest Belen Forest location (averages listed by management type in Table 2).

For sampling the canopy structure, a method was developed for determining an approximate canopy profile. Canopy sampling points were established at 4-m intervals along the north-south and east-west axis of the sampling location for a total of 13 points. At each canopy sampling point, a vertex hypsometer was used to measure the height of the lowest and highest canopy vegetation immediately above the point. The difference between highest and lowest vegetation was then calculated to determine the depth in meters of canopy structure directly above each sampling point. The values for each canopy sampling point were then combined to arrive at a cumulative structure depth for each sampling location (Fig. 2).

Percentage of canopy cover was measured using two methods. In most plots, percentage of canopy cover was estimated using the LAI 2000 Plant Canopy Analyzer (LI-COR, Lincoln, Nebraska, USA). The LICOR works by estimating the probability (from 0 to 1) of diffuse radiation passing from the upper atmosphere through the canopy (Welles 1990). In each sampling location, ten LI-COR measurements were taken within the 5-m radius and the average was used for subsequent analysis. Technical difficulties prevented LI-COR readings from some of the forest locations, so structure cover was first derived by calculating the percentage of canopy sampling plots with vegetation above them. These data, which were positively corre- lated with the LI-COR readings $(r=0.792)$, were then used in a single linear regression model to predict the missing LI-COR values ([Canopy Closure $]=6.227+$ 0.816 [Structure Cover]; $n=16, R^{2}=0.628, P<$ $0.0009)$. The resulting predicted values were then added to the LI-COR data to allow values for all points for percentage of canopy cover.

For each sampling location, altitude, aspect, and slope were also determined.

\section{Management Index}

Since one of the goals of this study was to find a way to quantify the effects of management intensification on the shade canopy, a Management Index was created that included all of the vegetation variables subjectively determined to be affected by management based on personal observation of major farm activities (for related articles on the use of this type of index for aquatic and terrestrial systems see Karr 1991 and O'Connell et al. 2000). Creation of the index involved weighting each of the selected variables equally along a scale from 0.0 to 1.0 , where 0.0 represents the least managed/most "natural" system and 1.0 represents the most managed system. The index values for each variable were then added together by location so that, since seven vegetative variables were included in this index, the total Management Index values ranged from 0.0 to a possible high of 7.0 (Table 1). 


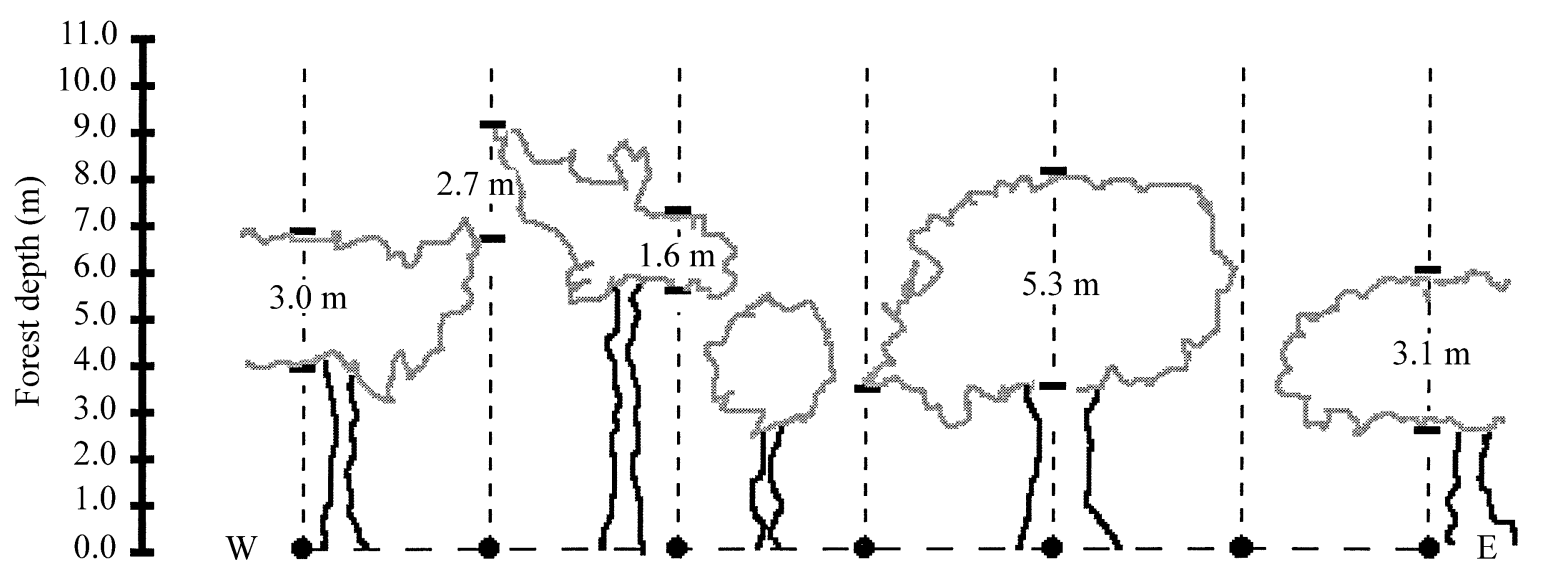

FIG. 2. Example of structure depth calculation. The line at bottom represents the E-W axis of a sampling location, with the seven canopy sampling points that would appear along it. The horizontal bars represent the actual high and low points of vegetation recorded along the E-W axis of Irlanda Restoration point number 3, and the values between the bars are the depth of structure between high and low. The total structure depth for this sampling location would therefore be $3.0+2.7$ $+1.6+5.3+3.1=15.7 \mathrm{~m}$, plus the sum of depths from the $\mathrm{N}-\mathrm{S}$ axis. The stylized trees are included to give a general sense of what this sampling location might have looked like, as well as the structural variation (e.g., small tree, single point of vegetation contact) that might not be captured by this method.

All of the variables included directly reflect management practices within the coffee agroecosystem, but were treated slightly differently in the Management Index. For tree species richness, for example, the 0.0 value was based on the average tree species richness for the forest reserve plots, on the assumption that expected tree species richness could vary depending on the native forest type present. The proportion of the average forest tree species richness (13 species) was calculated for each point and then subtracted from 1.0, so that a high value would represent a system managed for decreased shade tree diversity. Similarly, for average tree height, the 1.0 value was based on the point with the lowest average tree height on the assumption that more intensive management includes regular pruning that produces a lower average tree height. The 0.0 value for average tree height was based on the point with the overall highest average tree height, as the least intensive condition. The average tree height (ATH) val- ue for each point was then calculated as the proportion of the overall lowest value, then subtracted from 1.0 (Index Value $=1-$ [point ATH - low ATH] $/[$ high ATH - low ATH]). For this study, the low ATH = $6.21 \mathrm{~m}$, and the high ATH $=14.16 \mathrm{~m}$. The point with the highest value for structure depth was selected as the 0.0 value for this variable on the same assumption that more intensive management includes regular and dramatic pruning that will greatly reduce canopy structure. For both average tree height and structure depth, data were available only for plots with coffee, so no native forest comparisons were possible.

High coffee stem density is also assumed to be a component of more intensive management, so the point with the highest density was set as the 1.0 value and all others were set as proportions of this high value. Extremely high average coffee heights generally represent less intensive management, so the highest average height was set for the 0.0 value. Percentage of

TABLE 1. Average standardized values for variables included in the Management Index, and total Index value for each management system.

\begin{tabular}{|c|c|c|c|c|c|c|c|}
\hline \multirow[b]{2}{*}{ Vegetation variables } & \multicolumn{2}{|c|}{ Condition intensity } & \multirow[b]{2}{*}{ BelRus } & \multirow[b]{2}{*}{ IrlRes } & \multirow[b]{2}{*}{ IrlPrd } & \multirow[b]{2}{*}{ BelPrd } & \multirow[b]{2}{*}{ HamPrd } \\
\hline & Least $(0.0)$ & Most (1.0) & & & & & \\
\hline Tree species richness (no.) & 13 species & 0 species & 0.44 & 0.54 & 0.71 & 0.67 & 0.85 \\
\hline With epiphytes (\%) & $100 \%$ & $0 \%$ & 0.72 & 0.86 & 0.83 & 1.00 & 0.94 \\
\hline Average tree height $(\mathrm{m}) \dagger$ & $14.16 \mathrm{~m}$ & $6.21 \mathrm{~m}$ & 0.19 & 0.64 & 0.60 & 0.84 & 0.75 \\
\hline Structure depth (m) & $102.15 \mathrm{~m}$ & $0 \mathrm{~m}$ & 0.13 & 0.78 & 0.87 & 0.97 & 0.94 \\
\hline Canopy cover $(\%)$ & $100 \%$ & $0 \%$ & 0.08 & 0.46 & 0.41 & 0.52 & 0.85 \\
\hline Coffee bushes (no.) & 0 bushes & 196 bushes & 0.28 & 0.58 & 0.63 & 0.61 & 0.69 \\
\hline Average coffee height (m) & $4.03 \mathrm{~m}$ & $0 \mathrm{~m}$ & 0.18 & 0.46 & 0.39 & 0.46 & 0.68 \\
\hline Total Management Index & & & 2.02 & 4.27 & 4.50 & 5.08 & 5.71 \\
\hline
\end{tabular}

Notes: Actual values for least intensive condition (0.0) and most intensive condition (1.0) are shown. Abbreviations are: BelRus, Belen Rustic; IrlRes, Irlanda Restoration; IrlPrd, Irlanda Production; BelPrd, Belen Production; HamPrd, Hamburgo Production; IrlFor, Irlanda Forest; and BelFor, Belen Forest.

$\dagger$ See Methods: Management Index for average tree height (ATH) formula. 
presence and absence of epiphytes and percentage of canopy closure already ranged from 0.0 to 1.0 , so the inverse of each percentage was added to the Management Index. As a result, complete removal of epiphytes and a completely open canopy would have values of 1.0 in the Management Index. Actual values for least intensive and most intensive condition used for this study are shown in Table 1.

\section{Test of Management Index}

A principal components analysis (PCA) was used to confirm the Management Index. Unrotated factors were used to ensure that the first component accounted for the maximum amount of variance (Stevens 1986). The Management Index was then compared with the PCA first component using simple linear regression. In addition, each of the seven variables included in the index were compared to the PCA first component and the Management Index using simple linear regression. Variables with the lowest correlation were removed to form a hypothetical minimum variable index. These variables were then used in a five variable PCA for comparison with the minimum index.

\section{Butterfly sampling}

Butterfly diversity has been shown to stratify vertically in the forest canopy (DeVries et al. 1997), so two standard butterfly bait traps were set as close as possible to the center of each sampling location, one in the understory ( $\sim 1 \mathrm{~m}$ above the ground) and one in the canopy (hung from a branch of an emergent tree) (Kremen 1994, DeVries et al. 1997). Traps were set for a period of $8 \mathrm{~d}$ within each management system and baited with a mash of fermented plantain or banana before each sampling day. Traps were checked on alternate days within the 8-d period for a total of four samples per trap. Each location was visited at approximately the same time of day during each sample to ensure an equal period of time between samples (48 h). Trapping took place at the Tapachula site from 14 to 23 June 1998 and at the Huixtla site from 2 to 11 July 1998.

While Sparrow et al. (1994) noted that visual censuses were necessary as well to get a more complete assessment of the tropical forest community (primarily Pieridae and Papilionidae families), G. Austin (personal communication) commented that visual censuses are extremely hard to standardize, particularly if the researcher is not familiar with local butterfly fauna. Due to the short time period available for this study, and the importance of standardizing effort between treatments, sampling focused on the fruit-feeding guild of butterflies (primarily Nymphalidae) that are attracted to hanging traps. All captured individuals were either collected as voucher specimens for later identification, or recorded, marked, and released. Recaptures were recorded, but not counted as new sightings. Butterflies were identified using available field guides (DeVries
1987, de la Maza 1987). Voucher specimens were confirmed at the National Institute of Ecology in Mexico City (R. de la Maza, personal communication).

\section{Estimation of total butterfly species richness}

In order to estimate the total species richness of butterflies found within each management system, the software VACSYS was utilized, using the Michaelis-Menton function (Hanski and Gyllenberg 1997), to predict the asymptote of projected species accumulation curves. To verify these results, a second method of estimating total richness was used. The software package, COMDYN, developed by Nichols et al. (1998), uses a bootstrap approach to predict an estimate of total diversity. The details of the second approach, and citations where it has been used, are available online. ${ }^{2}$

\section{Statistical analyses}

One-way analysis of variance (ANOVA) was used to compare means for all of the vegetation variables, and assumptions of normality and equal variance were tested, using Lilifore's test of normality and Levene's test of homogeneity of variance. In the cases where assumptions of normality or equal variance could not be met, Kruskal-Wallis nonparametric test was used to compare means or distributions. Multiple comparisons were used to distinguish statistically different management systems. Tukey's honestly significant difference was used when (according to Levene's test of homogeneity of variance) the assumption of equal variance was not violated, and Dunnett's T3 was used when the assumption could not be met.

Estimates of total diversity were compared statistically by first using VACSYS to permute the order of acquisition of species used in constructing species accumulation curves. One hundred random permutations were performed to generate 100 estimates of total species richness, and these estimates were then randomly reassigned into two groups 10000 times using the software RANDMEAN (available online). ${ }^{3}$ RANDMEAN then evaluates how frequently it is possible to achieve the difference as great or greater than the actual difference observed, and uses this probability (Bonferroni transformed at $\alpha=0.05$ to adjust for compounding error rate) to derive the $P$ values of statistically significant difference. Simple linear regression was used to compare both estimation methods with the average Management Index value for each treatment.

\section{RESUlts}

\section{Vegetation data}

Table 2 presents the results of the one-way ANOVAs and multiple comparisons for all vegetation variables. It is important to note that, while the majority of results are significantly different $(\alpha=0.05)$, multiple com-

\footnotetext{
${ }^{2}$ URL: 〈http://www.mbr-pwrc.usgs.gov/software/comdyn.html〉

${ }^{3}$ URL: 〈http://research.amnh.org/ siddall/rand.html〉
} 
TABLE 2. Results of one-way ANOVA and multiple comparison tests for vegetation variables.

\begin{tabular}{|c|c|c|c|c|c|c|c|c|}
\hline Vegetation variables & IrlFor $^{\mathrm{a}}$ & BelFor $^{b}$ & BelRus $^{c}$ & $\operatorname{IrlRes}^{\mathrm{d}}$ & $\operatorname{IrlPrd}^{\mathrm{e}}$ & BelPrd $^{\mathrm{f}}$ & HamPrd $^{g}$ & $P$ \\
\hline Tree species richness (no.) & $13.3^{\mathrm{c}, \mathrm{d}, \mathrm{e}, \mathrm{f}, \mathrm{g}}$ & $12.5^{\mathrm{d}, \mathrm{e}, \mathrm{f}, \mathrm{g}}$ & $7.3^{\mathrm{a}, \mathrm{g}}$ & $6.0^{\mathrm{a}, \mathrm{b}}$ & $3.8^{\mathrm{a}, \mathrm{b}}$ & $4.3^{\mathrm{a}, \mathrm{b}}$ & $2.0^{\mathrm{a}, \mathrm{b}}$ & **** \\
\hline Tree abundance (no.) & $26.8^{\mathrm{c}, \mathrm{d}, \mathrm{e}, \mathrm{f}, \mathrm{g}}$ & 16 & $9.8^{\mathrm{a}}$ & $10.5^{\mathrm{a}}$ & $8.8^{\mathrm{a}}$ & $8.0^{\mathrm{a}}$ & $4.3^{\mathrm{a}}$ & $* * *$ \\
\hline With fruit or flowers (\%) & $2.0 \%$ & $4.0 \%$ & $5.0 \%$ & $0.0 \%$ & $6.0 \%$ & $0.0 \%$ & $12.6 \%$ & NS \\
\hline With epiphytes (\%) & $66.5 \% \mathrm{f}, \mathrm{g}$ & $32.5 \%{ }^{\mathrm{f}}$ & $28 \%$ & $13 \%$ & $17 \%$ & $0.0 \%$ a,b & $6.3 \% \mathrm{~m}^{\mathrm{a}}$ & $* * *$ \\
\hline Average tree height $(\mathrm{m})$ & $\ldots$ & $\cdots$ & $12.5^{\mathrm{de}, \mathrm{f}, \mathrm{g}}$ & $9.0^{\mathrm{c}}$ & $9.0^{\mathrm{c}}$ & $7.3^{\mathrm{c}}$ & $7.9^{\mathrm{c}}$ & $* * *$ \\
\hline Average tree dbh $(\mathrm{cm})$ & $\ldots$ & $\ldots$ & 11.8 & 8.8 & 11.4 & 9.7 & 8.8 & NS \\
\hline Structure depth $(\mathrm{m})$ & $\ldots$ & $\ldots$ & $88.4^{\mathrm{d}, \mathrm{e}, \mathrm{f}, \mathrm{g}}$ & $22.6^{\mathrm{cff}, \mathrm{g}}$ & $13.2^{\mathrm{c}, \mathrm{f}}$ & $3.1^{\mathrm{c}, \mathrm{d}, \mathrm{e}}$ & $5.3^{\mathrm{c}, \mathrm{d}}$ & $* * *$ \\
\hline Canopy cover (\%) & $\cdots$ & $\cdots$ & $92.3 \%{ }^{\mathrm{f}, \mathrm{g}}$ & $54.3 \%{ }^{\mathrm{f}, \mathrm{g}}$ & $58.8 \%{ }^{\mathrm{c}, \mathrm{g}}$ & $48.2 \%$ c,d & $14.5 \%$ c,d & $* * *$ \\
\hline Coffee bushes (no.) & N/A & N/A & 54.5 & 113.0 & 124.0 & 120.5 & 134.8 & NS \\
\hline Average coffee height (m) & N/A & N/A & $3.2^{\mathrm{d}, \mathrm{f}, \mathrm{g}}$ & $2.2^{\mathrm{c}, \mathrm{g}}$ & $2.4^{\mathrm{g}}$ & $2.1^{\mathrm{c}, \mathrm{g}}$ & $1.3^{\mathrm{c}, \mathrm{d}, \mathrm{e}, \mathrm{f}}$ & $* * *$ \\
\hline Altitude (m) & $926^{\mathrm{b}, \mathrm{c}}$ & $1166^{\mathrm{a}, \mathrm{d}, \mathrm{e}, \mathrm{f}, \mathrm{g}}$ & $1091^{\mathrm{a}, \mathrm{d}, \mathrm{f}}$ & $990^{\mathrm{b}, \mathrm{c}}$ & $1004^{\mathrm{b}}$ & $948^{\mathrm{b}, \mathrm{c}}$ & $1018^{\mathrm{b}}$ & *** $*$ \\
\hline Slope $(\%)$ & 24.5 & 88.7 & 70.0 & 52.3 & 28.3 & 33.0 & 41.8 & $*$ \\
\hline Aspect (degrees) & 135.5 & 209.5 & 217.3 & 146.5 & 142.3 & 261.3 & 272.0 & NS \\
\hline
\end{tabular}

Notes: See Table 1 for abbreviations. Different superscript letters represent management systems from which each system is significantly different. N/A means not applicable.

$* P<0.05 ; * * * P<0.001 ;$ NS, not significant.

parisons reveal that in most cases the difference is the result of the two forest reserves. The variables that are significantly different within the five coffee agroecosystems are tree species richness $(P<0.009)$, average tree height $(P<0.009)$, structure depth $(P<0.009)$, percentage of canopy cover $(P<0.009)$, and average coffee height $(P<0.009)$. Of the five coffee agroecosystems, only Belen Rustic is significantly different for every variable.

\section{Management Index}

The one-way ANOVA of the mean Management Index values for each coffee management system shows statistically significant differences among the five management systems $\left(F_{4,15}=60.564\right.$, df $=4, P<0.0009$; Fig. 3). A Tukey's multiple comparison test shows that Belen Rustic is significantly different than the other four systems and that Hamburgo Production is significantly different from all others (all at $\alpha=0.05$ level of significance). Simple linear regression between the Management Index and the PCA first component factor scores was highly significant (adjusted $R^{2}=0.977, P$ $<0.00009$ ).

\section{Test of Management Index}

The Principal Component Analysis (PCA) was significant, and the first component accounted for $63.3 \%$ of the variation in the original seven variables included in the Management Index. Unrotated factor scores are shown in Table 3 . The first component was significantly correlated with the Management Index $\left(r^{2}=0.995, F\right.$ $=3587.789, P<0.0001)$. Each of the variables was significantly correlated $(\propto=0.05)$ with the first component and the Management Index (Table 3). Removing variables with the lowest factor scores, first coffee density and fthen percentage epiphytes, produced six and five variable PCA first components that accounted for a progressively greater proportion of the variation (Table 4). The minimum variable index was also significantly correlated with the first component of the five variable PCA $\left(r^{2}=0.995, F=3920.698, P<0.0001\right)$.

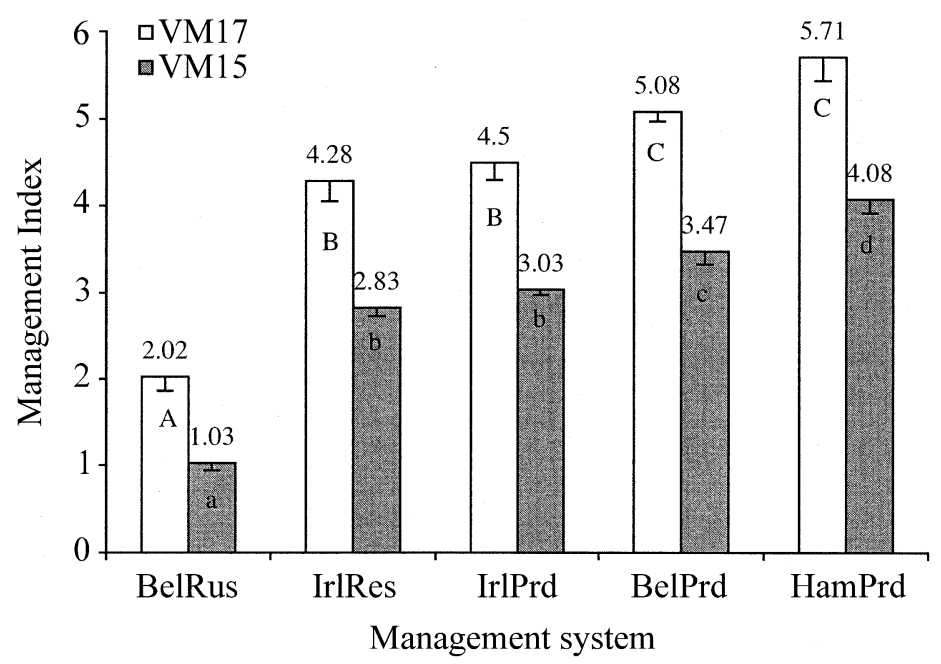

FIG. 3. Management Indices presented for each coffee management system (VMI7, Management Index with seven variables; VMI5, minimum Management Index using five variables with maximum value of 5.0). The average values for each management system are shown (error bars show $-1 \mathrm{SE}$ ). The letters in each column indicate mean values that are statistically distinct from one another $(\alpha=0.05)$. See Table 1 for abbreviations. 
TABLE 3. Principal component analysis (PCA) results for seven variables included in Vegetation Management Index (VMI).

\begin{tabular}{|c|c|c|c|c|c|c|c|c|}
\hline \multirow[b]{2}{*}{ Variable } & \multicolumn{2}{|c|}{ PCA } & \multicolumn{3}{|c|}{$\begin{array}{l}\text { PCA first component } \\
\text { regression }\end{array}$} & \multicolumn{3}{|c|}{ VMI regression } \\
\hline & 1st factor & 2nd factor & $r^{2}$ & $F$ & $P$ & $r^{2}$ & $F$ & $P$ \\
\hline Structural depth & 0.898 & 0.052 & 0.807 & 75.197 & $<0.0001$ & 0.821 & 82.519 & $<0.0001$ \\
\hline Average tree height & 0.869 & -0.156 & 0.754 & 55.305 & $<0.0001$ & 0.773 & 61.345 & $<0.0001$ \\
\hline Average coffee height & 0.845 & 0.121 & 0.714 & 44.946 & $<0.0001$ & 0.676 & 37.484 & $<0.0001$ \\
\hline Canopy openness & -0.859 & 0.183 & 0.739 & 50.872 & $<0.0001$ & 0.758 & 56.283 & $<0.0001$ \\
\hline Tree species richness & 0.742 & 0.397 & 0.550 & 22.021 & 0.0002 & 0.511 & 18.784 & 0.0004 \\
\hline Percentage with epiphytes & 0.674 & 0.434 & 0.455 & 15.014 & 0.0011 & 0.415 & 12.770 & 0.0022 \\
\hline Coffee density & -0.669 & 0.664 & 0.447 & 14.568 & 0.0013 & 0.495 & 17.619 & 0.0005 \\
\hline Eigenvalue & 4.466 & 0.863 & & & & & & \\
\hline Variance explained (\%) & 63.8 & 12.3 & & & & & & \\
\hline
\end{tabular}

Note: Unrotated factor scores are shown along with simple linear regression results against the PCA first component and Management Index.

\section{Estimation of total butterfly species richness}

A total of 35 butterfly species were recorded in this study. Of these, 13 were found exclusively in forest sampling locations and 13 were found exclusively in coffee locations (Appendix). Since butterflies were captured using baited traps, most of the species belong to the guild of fruit-feeding butterflies (Family Nymphalidae). Pairwise comparisons between VACSYS estimates of total richness in each management system or forest reserve area revealed that Irlanda Forest is significantly more diverse than all other areas, and that Belen Forest and Belen Rustic are significantly more diverse than the other coffee agroecosystems, but not significantly different from each other, and the remaining four systems were not significantly different from one another (Fig. 4). A Pearson's correlation between total species estimations from COMDYN and VACSYS revealed a highly significant correlation $(r=$ $0.982, P<0.0009)$.

\section{Coffee Management Index and butterfly species richness}

Simple linear regressions of the Management Index (MI) for butterfly species richness (SR) calculated by both estimation methods were significant $(\alpha=0.05)$. For VACSYS estimates, the linear regression equation was $\mathrm{SR}=33.98-4.67 \times \mathrm{MI}\left(n=5\right.$, adj. $r^{2}=0.78$, $F=15.081, P=0.03)$. For RANDMEAN estimates, the linear regression equation was $\mathrm{SR}=34.5-4.82$ $\times$ MI $\left(n=5\right.$, adj. $\left.r^{2}=0.93, F=57.14, P=0.005\right)$.

\section{DISCUSSION}

\section{Management Index and vegetation variables}

Previous work evaluating bird communities in coffee agroecosystems with different shade management practices demonstrates some of the ambiguity and limitations in the terms currently used to describe the shade canopy. The two studies used different terms to describe high- and low-shade conditions (traditional and modern in Calvo and Blake 1998; rustic and planted (Inga) shade in Greenberg et al. 1997b). Calvo and Blake (1998) found significant differences with higher bird diversity and abundance on the traditional farm, while Greenberg et al. (1997b) found similarly high overall diversity in both plantation types. While on the surface these results seem contradictory, fortunately both studies provide vegetation profiles and information on diversity of canopy trees. These vegetation profiles suggest that both shade types in Calvo and Blake (1998) are more intensive than the planted (Inga) shade in Greenberg et al. (1997b), thus, the changes in the bird community seem to occur at some intermediate level of management intensity. While adoption of common terminology has progressed since these studies were conducted (Moguel and Toledo 1999), these studies suggest the importance of characterizing vegetation

TABle 4. Principal component analysis (PCA) results with five or six variables included; shown with unrotated factor scores.

\begin{tabular}{lrrrrrr}
\hline \hline \multirow{2}{*}{\multicolumn{1}{c}{ Variables }} & \multicolumn{2}{c}{ 6-variable PCA } & & \multicolumn{2}{c}{ 5-variable PCA } \\
\cline { 2 - 3 } \cline { 5 - 6 } \cline { 5 - 6 } & 1st factor & 2nd factor & & 1st factor & 2nd factor \\
\hline Structural depth & 0.906 & -0.007 & & 0.914 & -0.135 \\
Canopy openness & -0.843 & 0.210 & & -0.870 & 0.108 \\
Average tree height & 0.850 & 0.310 & & 0.834 & -0.459 \\
Average coffee height & 0.854 & -0.235 & & 0.865 & 0.196 \\
Tree species richness & 0.773 & -0.373 & & 0.784 & 0.550 \\
Percentage with epiphytes & 0.708 & 0.578 & & & 3.652 & 0.582 \\
Eigenvalue & 4.083 & 0.680 & & 73.0 & 11.6 \\
Variance explained $(\%)$ & 68.0 & 11.2 & & & &
\end{tabular}




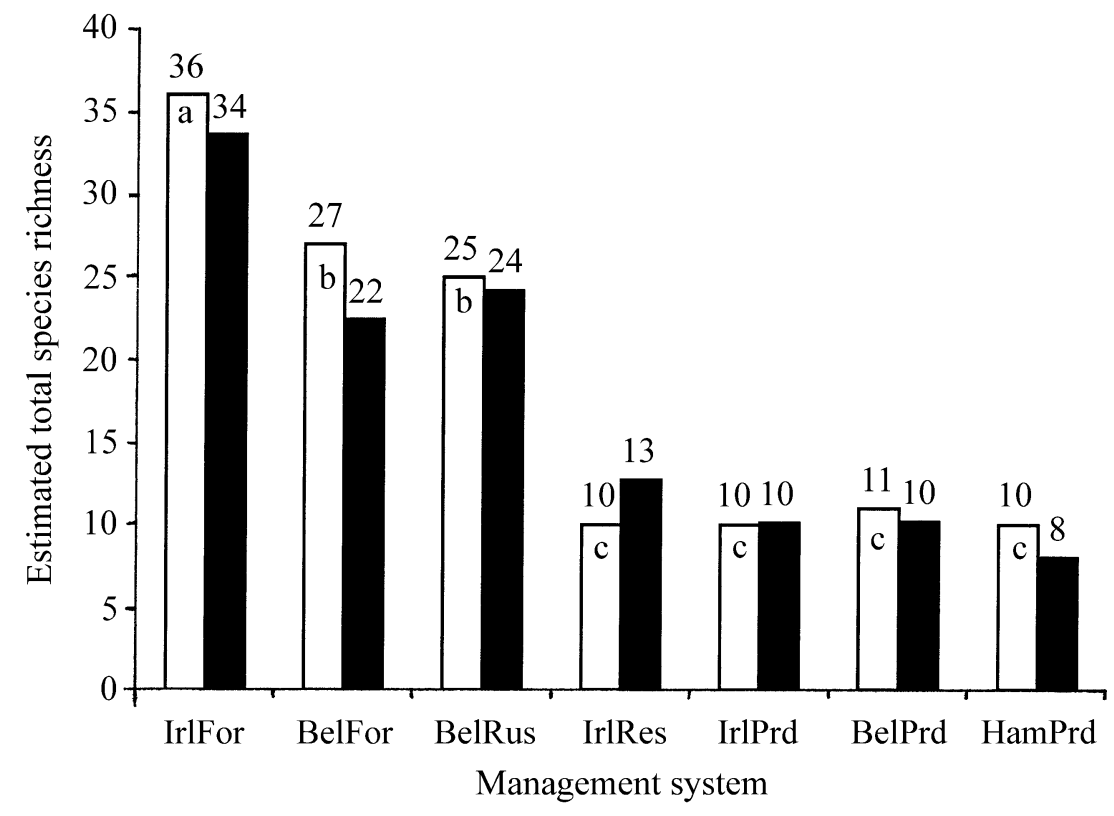

FIG. 4. Estimated total butterfly species richness based on VACSYS (white bars) and COMDYN (black bars). The letters in each bar indicate mean values that are statistically distinct from one another $(\alpha=0.05)$. See Table 1 for abbreviations.

management to help clarify contradictory results. Further standardization of vegetation data collection and reporting could be valuable for comparisons between different regions and taxa.

In this study, the results of vegetative sampling (Table 2) and analysis of the Management Index (Fig. 3) make clear that significant and measurable differences can be quantified between different management systems for shade-grown coffee. The principal variables explaining these differences were tree species richness, average tree height, structure depth, and percentage of canopy cover (Table 2). Significant differences also existed for average coffee height. As the dominant understory plant species on a coffee farm, it stands to reason that the coffee bushes might provide important habitat for biodiversity, and additional structural diversity.

Among the five shade coffee agroecosystems studied, we could distinguish three significantly different management systems: (1) Belen Rustic, with the lowest Management Index and higher shade cover, as well as tree species richness; (2) Irlanda Restoration and Irlanda Production, with intermediate Management Index values; and (3) Belen Production and Hamburgo Production, with the highest Management Index and lowest shade cover and tree species diversity (Fig. 3). Based on the Management Index, three vegetatively distinct management systems can be described according to Toledo and Moguel's categories (1996): rustic (Belen Rustic), commercial polyculture (Irlanda Restoration and Irlanda Production), and shaded monoculture (Belen Production and Hamburgo Production). Unshaded monoculture was not included in this study.
The ability of the Management Index to sort coffee agroecosystems demonstrates its potential for research and certification. By allowing the systematic quantification of the shade component of any coffee farm, and analyzing it along a scale of management intensity, this method provides statistical data to confirm the gestalt distinctions provided by Toledo and Moguel (1996). Furthermore, it is less prone to observer bias and allows researchers to assign ambiguous systems, like Irlanda Restoration, into clearly and empirically defined categories. These assignments are not static, particularly in the case of a system like Irlanda Restoration, where the restoration program has already reduced management intensity but the accompanying Management Index value won't respond until the shade canopy matures. This method has the additional advantage that it is region specific, which makes it possible for researchers to distinguish between the different shade management practices used in the regions where they work.

\section{Test of Management Index}

This study used Principal Components Analysis (PCA) to confirm that index values provide a good representation of the variation within the original dataset. PCA is a commonly used data reduction method in ecology (Stauffer et al. 1985). The high correlation with the PCA first component suggests that the Management Index captures the variation found in the variables as well as this established data reduction method. However, this is not a validation of the index. Independent data, preferably under a range of coffee growing conditions, will be needed for a true validation. 
These results suggest that the vegetation Management Index is a good approach for simplifying the complex range of vegetative variation found in coffee agroecosystems.

In general, all variables used were highly co-correlated, and significantly correlated with the PCA first component and the Management Index (Table 3). The structural depth variable developed for this study proved to be the variable with the highest correlation with each PCA first component conducted with 7, 6, and 5 variables (Tables 3 and 4). Data for this variable were relatively easy to collect and could replace or augment more labor- and equipment-intensive methods for measuring canopy structure and foliage complexity (MacArthur and Horn 1969, Pearson 1975).

The PCA first component explained a high proportion of the variance contained in the original seven variables $(63.8 \%)$. Reducing the number of variables, based on lowest correlation with the first component included in the PCA increases the proportion of variance explained (Table 4 ) to as high as $73.0 \%$ with coffee density and percentage of epiphytes removed. This suggests that a more precise index could be constructed with fewer variables. The index produced with five variables is just as correlated with the five-variable PCA first component as the Management Index is with the seven PCA first component. This hypothetical minimum variable index could be useful in cases where precision is necessary, such as defining management categories or evaluating management practices. The inclusion of coffee density and percentage of epiphytes may broaden the potential application of the Management Index for evaluating habitat use and comparing the effect of coffee intensification across taxa. These variables provide additional information on finer habitat structure. The low correlation of percentage of epiphytes may be due to the generally low level of epiphytes in this region compared to other coffee growing regions in Mexico (R. Greenberg, personal communication). Consequently, this variable may correlate better with management intensity in regions where epiphyte removal is more actively included in the pruning process.

For the Management Index, vegetation variables were weighted equally, which correlated strongly with the PCA first component. While equal weighting worked well for fruit-feeding butterflies, this might not be the case for other taxa or regions. More important than explanatory power in a particular study, equal weighting allows comparability between studies. Despite being a global export crop, local coffee cultivation practices and customs lead to tremendous variation by country and region. Equal weighting provides a common currency to identify coffee agroecosystems with similar levels of management intensity.

The disadvantage of PCA is that factor coefficients change with the addition of new data making comparisons between studies cumbersome. Standardized cal- culation methods for the Management Index can improve comparability by reducing the need for recalculating results for each study based on the data from the other. Alhough for this study, Management Index values were standardized based on the actual range of each variable, standardization for a more comprehensive index could be based on set values, such as consensus certification criteria, to improve the ease of comparison between research projects, coffee management practices, and coffee growing regions.

\section{Coffee Management Index and butterfly species richness}

Butterfly data reveal a pattern of decreasing butterfly species richness moving from the forest reserves, through the rustic system, and into the areas of more intensive coffee production (Fig. 4). For both estimation methods, butterfly species richness was significantly correlated with the Management Index. Two points stand out in particular from this analysis: First, while the estimate of butterfly species richness for Belen Rustic is slightly lower than the estimate for the neighboring forest reserve, this difference is not statistically significant. While this study did not evaluate whether the rustic management used at Finca Belen could in isolation support a diversity of butterflies comparable to a forest reserve, it seems reasonable that rustic coffee, at the very least, could extend the foraging range of fruit-feeding butterflies. Given the concern that these rustic systems might be population sinks that reduce the overall population viability for butterflies of conservation significance, more research is needed on mortality rates to substantiate conservation benefits.

Studies at the landscape level are lacking for coffee agroecosystems, but it is likely that forest reserves provide essential source populations for some species, as has been shown for moths in a Costa Rican agricultural landscape (Ricketts et al. 2001). An example of this comes from Finca Belen's forest, where Archeoprepona phaedra aelia was found, which is a threatened butterfly species through most of its range in Chiapas. Soconusco is one of the only areas where healthy populations remain, and the sighting in this study lends credence to the argument that the health of the local population is due at least in part to the presence of forest patches like the ones at Finca Belen and Finca Irlanda (de la Maza and de la Maza 1993). These patches should not be overly romanticized, however, as butterfly species indicative of disturbance were found in both forest patches. Still, pristine or not, these fragments are in many cases all that remain of original forest habitat. Conserving these fragments, and the rustic coffee that often surrounds and buffers them, should remain a central part of all shade coffee development strategies. Interestingly, the $y$-intercept for both regressions was near the estimated species richness for the Irlanda Forest (36 species). 
Second, in spite of the fact that the Management Index demonstrates a significant increase in management intensity in Hamburgo Production (Fig. 3), the estimate of total butterfly species richness in this system is statistically indistinguishable from that of the three systems that had intermediate levels of management intensity. We used linear regression to compare butterfly species richness with the Management Index because we could not determine the shape of the loss curve due to the lack of values between Rustic and Restoration treatments. The lack of difference for Hamburgo Production may suggest that this curve is nonlinear across the intensity gradient with sharper declines at lower Management Index values. Fruit-feeding butterflies as a guild, therefore, may be extremely sensitive to increases in management intensity within coffee agroecosystems, and only rustic systems seem to be capable of supporting significant species richness. Further evaluation would help to identify which subsets of this guild are most sensitive to changes in the composition of forest communities (de la Maza and Soberón 1998).

With this in mind, it is worthwhile to talk briefly about the lack of butterfly species richness found in Irlanda Restoration. While this result is initially surprising, given the effort at the included sampling locations to restore native tree species to produce a traditional, rustic shade, it may be partly explained by the fact that many of the planted trees are still young and lack sufficient shade, structural complexity, and fruit or flower production to attract forest butterfly species. This suggests that, given enough time with greater maturity, this relatively young restoration area will, as with Belen Rustic, increase in vegetative and structural diversity, and increased fruit production may be followed by an increase in butterfly species richness. Since extensive information exists on butterfly and caterpillar host-plant associations, it would be extremely valuable to do a more comprehensive botanical survey of the area to search specifically for plant families that provide resources for butterflies. With this information, it would be possible to alter the restoration plan so that it includes enrichment plantings for as wide a range of associate species as possible, and in this way more completely restores rustic conditions to the area.

Another noteworthy consideration is the lack of information regarding nectivorous butterflies, not included in this study. This guild of butterflies could benefit from more intensive management and could represent a conservation trade-off. While the mid-elevation slopes of the Sierra Madre de Chiapas were covered in broadleaf forest before conversion to coffee in the early 1900s, steep slopes in this region may have produced regular landslides and forest openings important to these butterflies. The expansion of coffee agriculture throughout the region may have also allowed range extensions and altitudinal movements through a dryer and warmer microclimate and in- creased abundance of flowers in the herbaceous ground cover. More research is needed to determine if open agriculture may provide conservation benefits for some nectivorous butterflies and other biodiversity.

\section{CONCLUSION}

The results of this study suggest that butterflies are highly sensitive to increases in management intensity. More detailed and exhaustive research is necessary to explore whether they can serve as reliable and efficient indicators of ecological change, including the establishment of permanent plots that can be monitored throughout the year to capture temporal variations (DeVries et al. 1997). It would also be extremely valuable to expand butterfly sampling to include nectarfeeding families, as they represent the majority of butterfly species, a vital component of overall diversity, and some of Mexico's rarest species (Sparrow et al. 1994, de la Maza and Soberón 1998).

Perhaps more importantly, this study highlights the utility of the Management Index for quantifying differences in the management of shade coffee production systems, which previously had only been distinguished using qualitative, gestalt categories. This approach could provide the basis for a standardized vegetation sampling protocol that could link certification criteria and programs with biodiversity evaluation and monitoring efforts. If these or similar data were routinely collected for research or during the certification process, scientific results would be more comparable using meta-analyses. This would also facilitate comparisons between farms and regions during follow-up monitoring to measure conservation success. Given the rising interest in using shade coffee certification as a marketbased mechanism for protecting shade coffee agroecosystems, it would be particularly useful to combine the application of this Management Index with an evaluation of fruit-feeding butterfly species richness to evaluate whether these new programs are recognizing real differences in management of the shade canopy, and whether the differences are meaningful for the conservation of biodiversity.

\section{ACKNOWLEDGMENTS}

We wish to thank Walter Peters and the ISMAM cooperative for allowing us to conduct this study on their farms and for giving us support throughout the time that we were conducting the study. We also thank ECOSUR-Tapachula and Guillermo Ibarra-Núñez and Alvaro Garcia-Ballinus for providing logistical support and access to laboratory facilities, and Ivette Perfecto and John Vandermeer for advice and consultation throughout the process of research and writing. Javier de la Maza helped with the design of the butterfly traps, and Roberto de la Maza corroborated butterfly identification. Darci Andresen, Jay West, and Daniel Griffith helped with data collection in the field. Gary Fowler, Herb Wagner, and Matthew Kotchen assisted with analysis. Two anonymous reviewers and David Andow provided helpful comments that improved the manuscript. This study was partially funded by the Latin American and Caribbean Study Program, the School of Natural Resources and Environment, and the Horace Rack- 
ham Graduate School of the University of Michigan. In addition, this work partially funded by the Kalamazoo Audubon Society and NSF grant number CEB-9981526.

\section{Literature Cited}

Brown, K. S. 1996. The use of insects in the study, inventory, conservation and monitoring of biological diversity in $\mathrm{Neo}$ tropical habitats, in relation to land use systems. Decline and Conservation of Butterflies in Japan III:128-149.

Brown, K. S. 1997. Diversity, disturbance, and suitable use of Neotropical forests: insects as indicators for conservation monitoring. Journal of Insect Conservation 1:1-18.

Calvo, L., and J. Blake. 1998. Bird diversity and abundance on two different shade coffee plantations in Guatemala. Bird Conservation International 8:297-308.

de la Maza E. J., and R. de la Maza E. 1993. Mariposas de Chiapas. Espejo de Obsidiana, New York, New York, USA.

de la Maza E. R. G., and J. Soberón. 1998. Morphological grouping of Mexican butterflies in relation to habitat association. Biodiversity and Conservation 7:927-944.

de la Maza Ramírez, R. 1987. Mariposas Mexicanas: Guía para su colecta y determinación. Fondo de Cultura Económica, Mexico, D.F.

DeVries, P. J. 1987. The butterflies of Costa Rica and their natural history. Princeton University Press, Princeton, New Jersey, USA.

DeVries, P. J., D. Murray, and R. Lande. 1997. Species diversity in vertical, horizontal, and temporal dimensions of a fruit-feeding butterfly community in an Ecuadorian rainforest. Biologicla Journal of the Linnaen Society 62:343364.

Greenberg, R., P. Bichier, A. C. Angon, and R. Reitsma. 1997a. Bird populations in shade and sun coffee plantations in Central Guatemala. Conservation Biology 11:448459.

Greenberg, R., P. Bichier, and J. Sterling. 1997b. Bird populations in rustic and planted shade coffee plantations of eastern Chiapas, Mexico. Biotropica 29(4):501-514.

Groombridge, B., editor. 1992. Global biodiversity. Chapman and Hall, London, UK.

Hamer, K. C., J. K. Hill, L. A. Lace, and A. M. Langan. 1997. Ecological and biogeographical effects of forest disturbance on tropical butterflies of Sumba, Indonesia. Journal of Biogeography 24:67-75.

Hanski, I., and M. Gyllenberg. 1997. Uniting two general patterns in the distribution of species. Science 275 : (5298)397-400.

Karr, J. R. 1991. Biological integrity: a long-neglected aspect of water resource management. Ecological Applications 1: 66-84.

Kremen, C. 1992. Assessing the indicator properties of species assemblages for natural areas monitoring. Ecological Applications 2:203-217.

Kremen, C. 1994. Biological inventory using target taxa: a case study of the butterflies of Madagascar. Ecological Applications 4:407-422.

Lawton, J. H., et al. 1998. Biodiversity inventories, indicator taxa and effects of habitat modification in tropical forest. Nature 391:72-75.

MacArthur, R. H., and H. S. Horn. 1969. Foliage profile by vertical measurements. Ecology 50:802-804.

Martin, T. E., and G. R. Geupel. 1993. Nest-monitoring plots: methods for locating nests and monitoring success. Journal of Field Ornithology 64:507-519.
Moguel, P., and V. M. Toledo. 1996. El café en México: ecología, cultura indígena y sustentabilidad. Ciencias 43: 40-51.

Moguel, P., and V. M. Toledo. 1999. Biodiversity conservation in traditional coffee systems in Mexico. Conservation Biology 12:1-11.

Nichols, J. D., T. Boulinier, J. E. Hines, K. H. Pollock, and J. R. Sauer. 1998. Inference methods for spatial variation in species richness and community composition when not all species are detected. Conservation Biology 12:13901398.

Noss, R. F. 1990. Indicators for monitoring biodiversity: a hierarchical approach. Conservation Biology 4:355-364.

O'Connell, T. J., L. E. Jackson, and R. P. Brooks. 2000. Bird guilds as indicators of ecological condition in the central Appalachians. Ecological Applications 10:1706-1721.

Oliver, I., and A. J. Beattie. 1993. A possible method for the rapid assessment of biodiversity. Conservation Biology 7 : 562-568.

Pearson, D. L. 1975. The relation of foliage complexity to ecological diversity of three Amazonian bird communities. Condor 77:453-466.

Perfecto, I., A. Mas, T. Dietsch, and J. Vandermeer. 2003. Conservation of biodiversity in coffee agroecosystems: a tri-taxa comparison in southern Mexico. Biodiversity and Conservation 12:1239-1252.

Perfecto, I., R. A. Rice, R. Greenberg, and M. E. Van der Voort. 1996. Shade coffee: a disappearing refuge for biodiversity. BioScience 46:598-608.

Perfecto, I., and R. Snelling. 1995. Biodiversity and the transformation of a tropical agroecosystem: ants in coffee plantations. Ecological Applications 5:1084-1097.

Ricketts, T. H., G. C. Daily, P. R. Ehrlich, and J. P. Fay. 2001. Countryside biogeography of moths in a fragmented landscape: biodiversity in native and agricultural habitats. Conservation Biology 15:378-388.

Sparrow, H. P., T. D. Sisk, P. R. Ehrlich, and D. D. Murphy. 1994. Techniques and guidelines for monitoring Neotropical butterflies. Conservation Biology 8:800-809.

Stauffer, D. F., E. O. Garton, and R. K. Steinhorst. 1985. A comparison of principal components from real and random data. Ecology 66:1693-1698.

Stevens, J. 1986. Applied multivariate statistics for the social sciences. Lawrence Erlbaum Associates, Hillsdale, New Jersey, USA.

Toledo, V. M., and P. Moguel. 1996. Searching for sustainable coffee in Mexico: the important of biological and cultural diversity. Pages 163-173 in R. A. Rice, A. M. Harris, and J. McLean, editors. Proceedings from the First Sustainable Coffee Congress, Smithsonian Migratory Bird Center, Smithsonian Institution, Washington, D.C., USA.

Welles, J. M. 1990. Some indirect methods of estimating canopy structure. Pages 31-43 in J. Norman and N. Goel, editors. Instrumentation for studying vegetation canopies for remote sensing in optical and thermal infrared regions. Harwood Academic, London, UK.

Wood, B., and M. P. Gillman. 1998. The effects of disturbance on forest butterflies using two methods of sampling in Trinidad. Biodiversity and Conservation 7:597-616.

Wunderle, J. M., and S. C. Latta. 1996. Avian abundance in sun and shade coffee plantations and remnant pine forest in the Cordillera Central, Dominican Republic. Ornithologia Neotropical 7:19-34.

\section{APPENDIX}

A table showing the number of individuals and species of fruit-feeding butterflies trapped at all sites in Soconusco in 1998 is available in ESA's Electronic Data Archive: Ecological Archives A013-022-A1. 